\title{
CONTROL OF INSECT PESTS IN PERSIMMON WITH SPRAY OILS
}

\author{
R.E. GASKIN ${ }^{1}$, B.H. ROHITHA ${ }^{2}$ and P.T. HOLLAND ${ }^{2}$ \\ ${ }^{I}$ NZ Forest Research Institute Ltd, Private Bag 3020, Rotorua \\ ${ }^{2}$ HortResearch, Ruakura Research Centre, Private Bag 3123, Hamilton
}

\begin{abstract}
The efficacy and safety to plants of mineral spray oils for use against mealybugs were assessed in field trials on persimmon. Repeated applications of oil and adjuvant-enhanced oil in the three months prior to harvest had no deleterious effects on fruit size or quality. Fortnightly applications of such oils in a commercial orchard maintained fruit insectfree. Oil sprays, enhanced with alkylsilicone adjuvant, provided significant control of mealybugs, and mites, in a persimmon orchard subjected to intensive pest pressure close to harvest. Addition of oil to insecticide used at half the recommended rate gave equivalent insect control to the full-rate insecticide regime. Oil had no effect on insecticide residues, which were halved in the half-rate treatment.

Keywords: pest control, mineral oil, alkylsilicones, pesticide residues, persimmon
\end{abstract}

\section{INTRODUCTION}

The use of mineral oils as environmentally benign materials with useful insecticidal properties is increasingly attractive, as consumer concerns over pesticide residues in produce continue to grow and our export markets impose more stringent residue controls. Oils are exempt from Maximum Residue Limit (MRL) requirements and the withholding periods to which synthetic insecticides are subject, thereby offering the potential to produce pest-free fruit that can meet strict export quarantine and residue standards.

It is well known that oils, both mineral and vegetable, can kill insects (Martin and Woodcock 1983), but they depend upon physical contact and have no residual activity (Johnson 1980); therefore, complete spray coverage of the target is essential. A new class of agrichemical adjuvants, the alkylsilicones (AS), can greatly enhance the spreading of oils (Policello et al. 1995). In theory, such enhanced spread should increase the insecticidal activity of an oil.

A particularly troublesome quarantine pest on persimmon is the mealybug (Pseudococcus longispinus), which resides under the calyx of fruit, thereby avoiding contact with many pesticide sprays. AS-enhanced oil sprays could potentially access such sites and improve contact with these cryptic pests. Additionally, if the effectiveness of existing chemical insecticides could be increased with enhanced oils it may allow for a reduction in chemical rates and reduce residues proportionately.

The primary concern in the use of oils on fruit crops is their potential for phytotoxicity. While pest control is likely to be improved by applying higher rates of oil, this increases the risk of damage to fruit (McKenna and Steven 1993).

The present studies were directed at (i) increasing the insecticidal activity of mineral oil, thereby providing a means of pest control on persimmons during the critical pesticide-withholding period and into harvest, and (ii) determining if AS surfactant-enhanced oil could increase the efficacy of an insecticide, enabling lower rates to be used and minimising residues in fruit at harvest. 


\section{Phytotoxicity of oil sprays}

\section{METHODS}

Mineral oil (Shellspray; Shell Chemicals) and AS-enhanced oil (containing 5\% v/v Y-12780 alkylsilicone; OSi Specialties Inc., USA) were applied at 1\% and 2\% v/ $\mathrm{v}$, to fruit-bearing persimmon trees (Diospros kaki L. cv. Matsumoto Wase Fuyu, 2$3 \mathrm{~m}$ tall) on five different dates approximately two weeks apart (24 February-18 April). Trees were subject to a standard insecticide regime (NZ Persimmon Export Council 1994a) until two weeks prior to the study. Sprays were applied (15 randomly selected trees per treatment) at 1500 litres/ha equivalent (research hand sprayer, D4-45 nozzle, $250 \mathrm{KPa}$ ) between 8-11 am. Trees and fruit were visually examined fortnightly for phytotoxicity, with a final assessment on fruit (5 per tree) at harvest (18 May). Additionally, chlorophyll fluorescence $(\mathrm{CF})$ measurements were made fortnightly on treated and control trees ( 2 leaves per tree) with a Morgan CF-1000 meter to monitor any treatment-induced stress (Lichtenthaler and Rinderle 1988).

\section{Effect of late-season airblast applications on fruit quality and pest control}

Three blocks (4 rows x 25 trees; cv. Japanese Fuyu) in a commercial orchard were randomly allocated to treatments. These blocks were subject to a standard programme of chemical insecticides (NZ Persimmon Export Council 1994a) until 4 March. The control continued to receive this programme through to harvest. Three applications of oil and AS-enhanced oil, both at $1 \% \mathrm{v} / \mathrm{v}$ (Table 1), were made to separate blocks by airblast sprayer (1500 litres/ha) at fortnightly intervals (17 March-26 April). All fruit from the middle two rows of each block (50 trees) were harvested on 23 May. All fruit from each tree were individually weighed and graded for export as "fancy", "select", or "reject" (NZ Persimmon Export Council 1994b), and data subjected to analysis of variance to determine any differences between treatments. Insect infestation was determined on 100 randomly selected fruit from the middle rows of each treatment. The calyx was removed and insects present counted and identified under a microscope. The incidence of cavity beneath the fruit calyx, which may provide a better refuge for cryptic pests, was also recorded.

\section{Effect of reduced-rate pesticide sprays on pest control and residues in fruit}

Forty five fruit-bearing persimmon trees (cv. Japanese Fuyu, 2-3 m tall) were allocated to a completely randomised block design of 5 treatments (including control) $\mathrm{x}$ 9 replicates. All trees were treated with fortnightly airblast applications at $70 \mathrm{ml} / 100$ litres of Attack (permethrin $25 \mathrm{~g} /$ litre + pirimiphos-methyl $475 \mathrm{~g} /$ litre; Crop Care Holdings Ltd) until 20 March. Two weeks later laboratory-bred mealybugs ( $P$. longispinus) were introduced onto fruit on all trees. Pieces of sprouted potato containing mealybugs were tied onto the calyx of 7 randomly selected, tagged fruit on every tree. In total, approximately 8000 mealybugs were released on 315 fruit. Full- and reduced-rate diazinon (Averte WP; $450 \mathrm{~g} / \mathrm{kg}$ diazinon $+22.5 \mathrm{~g} / \mathrm{kg}$ permethrin; Ciba-Geigy) treatments (Table 2) were applied to experimental trees on 18 April and repeated on 2 May, two weeks after mealybug infestation, by which time all mealybugs had moved out from potato sprouts. A further application, of the enhanced oil treatment only, was made within the pesticide withholding period, on 16 May. Sprays were applied with a research hand sprayer as described previously. Fruit were harvested on 30 May. Six randomly selected fruit were sampled, in addition to all tagged fruit, on each tree and insect infestation on all fruit was determined as described previously. Insect data underwent $\log (x+1)$ transformations prior to analysis of variance to compare differences among treatments on the basis of numbers of live insects present. Pesticide residue decay curves were established for diazinon, permethrin and pirimiphos-methyl. Randomly selected fruit (two replicates of 5 fruit each) were harvested at regular intervals up to 28 days after the last pesticide spray and stored deep frozen prior to residue analysis using methanol extraction, toluene partition, carbon column cleanup (Holland and McGhie 1988), followed by GC determination (Holland et al. 1994).

\section{Phytotoxicity tests}

\section{RESULTS AND DISCUSSION}

No damage due to application of any oil treatment was observed on fruit (75 per 
treatment) or foliage throughout this study. Additionally, CF measurements provided no evidence for any damaging effects of spray treatments on the photochemical efficiency of foliage, as no treatment means differed significantly $(\mathrm{P}<0.05)$ from the unsprayed control (data not presented). This indicates that oil and AS-enhanced oil sprays can safely be applied at regular intervals to persimmon, from February through to harvest.

\section{Airblast applications}

Oil treatments had no deleterious effects on fruit size, with all means falling within the "fancy"/"select" grade (Table 1). There were no differences $(\mathrm{P}<0.05)$ between the insecticide control and oil treatments in percentage of fruit graded "fancy". No statistical analysis of insect data was possible due to very low levels of infestation. No insect damage was detected and neither mealybugs nor leafroller larvae were found on any fruit. While the pest pressure in this well-managed commercial orchard was too low to distinguish any differences between oil treatments, both were effective in maintaining the insect-free status during the 11 weeks pre-harvest.

TABLE 1: Effect of oil treatments on size and quality of persimmon fruit.

\begin{tabular}{lcccc}
\hline Treatment & $\begin{array}{c}\text { Total no. of } \\
\text { fruit assessed }\end{array}$ & $\begin{array}{c}\text { Mean wt }(\mathrm{g}) \\
\pm \text { SD }\end{array}$ & $\begin{array}{c}\text { Mean grade } \\
\pm \text { SD }\end{array}$ & \% "Fancy" \\
\hline Control & 1085 & $223 \pm 25$ & $1.30 \pm 0.15$ & 72 \\
Oil & 980 & $239 \pm 18$ & $1.31 \pm 0.13$ & 74 \\
Enhanced Oil & 1015 & $219 \pm 18$ & $1.45 \pm 0.12$ & 67 \\
\hline
\end{tabular}

${ }^{1}$ Fancy $=1 ;$ Select $=2 ;$ Reject $=3$

\section{Reduced rate sprays}

The numbers of mealybugs present on infested fruit (Table 2) confirmed that all treatments gave highly significant control of mealybugs compared with the untreated (since late-March) control. The half-rate insecticide+AS-enhanced oil provided control equal to full-rate insecticide and better than half-rate insecticide or the enhanced oil treatment alone. Mealybug numbers on the randomly sampled fruit were too low to be analysed, but showed similar trends (Table 2). Leafroller numbers were generally too low overall for analysis (Table 2).

TABLE 2: Insects per fruit (transformed means) present on deliberately infested and randomly selected fruit treated with full and half rate insecticides and oils.

\begin{tabular}{lccccc}
\hline \multirow{2}{*}{$\begin{array}{l}\text { Insecticide } \\
\text { treatment }\end{array}$} & \multicolumn{2}{c}{ "Infested" fruit } & \multicolumn{3}{c}{ Random fruit } \\
\hline mealybug & mite & mealybug & mite & leafroller \\
\hline Half rate $^{1}$ & $3.9(0.58)^{* * *}$ & $0.9(0.19)^{* * *}$ & 0.4 & 0 & 0.2 \\
Enhanced oil $^{2}$ & $7.2(0.78)^{* *}$ & $2.1(0.30)^{* *}$ & 0.3 & 0.7 & 0 \\
Half rate $^{1}+$ & $8.6(0.87)^{* *}$ & $0.8(0.20)^{* *}$ & 0.8 & 0.1 & 0.5 \\
$\quad \begin{array}{c}\text { enhanced oil } \\
\text { control (untreated }\end{array}$ & $2.2(0.46)^{* *}$ & $1.0(0.18)^{* *}$ & 0.2 & 0 & 0 \\
$\quad$ since March) & $22.0(1.37)$ & $5.5(0.71)$ & 2.0 & 0 & 0.2 \\
\hline
\end{tabular}

1 Averte applied on 18 April and 2 May; full rate $112 \mathrm{~g} / 1001$, half rate $56 \mathrm{~g} / 1001$.

$21 \%(\mathrm{v} / \mathrm{v})$ Shellspray containing 5\% Y-12780. Additional spray application on 16 May. 3 assessed over all fruit sampled

** significantly different from the untreated control at $P<0.01$ level.

Mite numbers (tydeid mites and others) on the randomly sampled fruits were also extremely low and no analysis was possible as a result. Mites were not introduced with the mealybug potato cultures, but mealybugs, through their production of honeydew 
and sooty moulds, are known to encourage the proliferation of mites (D. Steven, pers. comm.), and they were present on mealybug infested fruit in sufficient numbers to evaluate the effect of treatments. All spray treatments reduced mite numbers significantly (Table 2 ). Half-rate insecticide+enhanced oil again reduced mite numbers most, although differences between treatments were not significant $(\mathrm{P}<0.05)$.

TABLE 3: Pesticide residues (mg/kg whole fruit) in persimmons treated with full and half rates of insecticide.

\begin{tabular}{lrccccc}
\hline $\begin{array}{l}\text { Insecticide } \\
\text { treatment }\end{array}$ & $\begin{array}{c}\text { Sample } \\
\text { date }\end{array}$ & $\begin{array}{c}\text { Days } \\
\text { after } \\
\text { treatment }\end{array}$ & $\begin{array}{c}\text { Fruit wt } \\
(\mathrm{g})\end{array}$ & diazinon & permethrin & $\begin{array}{c}\text { Residue } \\
\text { pirimiphos- } \\
\text { methyl }\end{array}$ \\
\hline Full rate & $9 / 05$ & 7 & 101 & 0.40 & 0.13 & $0.03^{1}$ \\
& $16 / 05$ & 14 & 129 & 0.14 & 0.11 & nd $^{2}$ \\
& $23 / 05$ & 21 & 130 & 0.10 & 0.11 & nd \\
& $30 / 05$ & 28 & 129 & 0.04 & 0.17 & nd \\
Half rate & $9 / 05$ & 7 & - & - & - & - \\
& $16 / 05$ & 14 & 134 & 0.04 & 0.08 & nd \\
& $23 / 05$ & 21 & 130 & 0.02 & 0.12 & nd \\
& $30 / 05$ & 28 & 117 & nd & 0.05 & nd \\
Half rate + & $9 / 05$ & 7 & 96 & 0.11 & 0.17 & $0.02^{1}$ \\
AS enh. oil & $16 / 05$ & 14 & 98 & 0.04 & 0.12 & nd \\
& $23 / 05$ & 21 & 116 & 0.02 & 0.08 & nd \\
& $30 / 05$ & 28 & 132 & nd & 0.08 & nd \\
Control & $9 / 05$ & - & - & nd & 0.06 & $0.02^{1}$ \\
\hline
\end{tabular}

${ }^{1}$ sampled on $9 / 05$, ie 50 days after airblast treatment with Attack

$2 \mathrm{nd}$; not detected (less than $0.01 \mathrm{mg} / \mathrm{kg}$ ).

There was no external insect damage on any fruit, nor was there any association between any of the treatments and the occurrence of calyx cavity (data not presented). The efficacy of oil spray without the benefit of an AS "enhancer" was not tested in this study. There is a need to determine whether such a treatment could provide equivalent pest control to the AS-enhanced oil spray, as it would offer substantial cost benefits.

AS-enhanced oil had no effect on residues (Table 3), as has been reported previously for organosilicone surfactants (Walker et al. 1992; Stevens et al. 1994), and diazinon levels were more than halved in the half-rate treatment. These results indicate that the withholding period of at least 28 days could be reduced to 14 days for half-rate treatments. At this time, diazinon residues from half-rate sprays were $0.1 \mathrm{mg} /$ $\mathrm{kg}$ which is less than half the MRL for export to Japan. The most stringent MRL for permethrin is demanded by Singapore $(0.1 \mathrm{mg} / \mathrm{kg}$ pending $)$, and this was also achieved approximately 14 days after the last spray of half-rate treatment (Table 3). Pirimiphosmethyl residues required approximately 50 days after treatment to decline to a "nil" level $(0.02 \mathrm{mg} / \mathrm{kg})$, as required by the Australian and SE Asian markets, after intensive applications (six treatments during Jan-March) of the pesticide.

\section{CONCLUSIONS}

The use of an enhanced oil+half-rate insecticide regime up to 14 days prior to harvest could provide insect control on persimmons for longer than is currently possible, while still achieving acceptable MRLs. In situations where fruit are subject to intensive pest pressure in the immediate pre-harvest period, oil formulations alone could provide significant pest control in the absence of pesticides. Alternatively, in orchards with low pest infestation, oil sprays could safely substitute for insecticides in the late season. 


\section{ACKNOWLEDGEMENTS}

Thanks to Bruce Cameron and Brent Wilcox for use of their orchards and to Arthur Vanner, Annette Ah-Chee and Joe Taylor for their valuable technical assistance. Colin Malcolm undertook residue analysis. Funds for this research were provided by the Agricultural and Marketing Research and Development Trust (AGMARDT), the Foundation for Research, Science and Technology, the Persimmon Export Council and OSi Specialties Inc. (USA).

\section{REFERENCES}

Holland, P.T. and McGhie, T.K., 1988. Multi-residue method for determination of pesticides in kiwifruit, apples and berryfruit. J. Assoc. Offic. Anal. Chem. 66: 1003-1008.

Holland, P.T., McNaughton, D.E. and Malcolm, C.P., 1994. Multi-residue analysis of wines by solid phase extraction. J. AOAC International 77: 79-86.

Johnson, W.T. 1980. Spray oils as insecticides. J. Aboriculture 6: 169-174.

Lichtenthaler, H.K. and Rinderle, U., 1988. The role of chlorophyll fluorescence in the detection of stress conditions in plants. In: Critical Reviews in Analytical Chemistry, 9; CRC Press, Boca Raton: s29-s85.

Martin, H. and Woodcock, D. 1983. The Scientific Principles of Crop Protection. Edward Arnold, London, 486 pp.

McKenna C.E. and Steven, D., 1993. Phytotoxicity to kiwifruit of oil sprayed after flowering. Proc. 46th N.Z. Plant Prot. Conf.: 75-79.

NZ Persimmon Export Council Ltd, 1994a. Persimmon Spray Diary. NZ Persimmon Export Council Ltd, P O Box 1417, Wellington.

NZ Persimmon Export Council Ltd, 1994b. Quality Manual. NZ Persimmon Export Council Ltd, P O Box 1417, Wellington.

Policello, G.A., Stevens, P.J.G., Gaskin, R.E., Rohitha, B.H. and McLaren, G.F., 1995. Alkylsilicones for agricultural oils and oil-based formulations. Proc. Fourth Int. Symp. on Adjuvants for Agrochemicals, FRI Bulletin No. 193: 303307.

Stevens, P.J.G., Walker, J.T.S., Shaw, P.W. and Suckling, D.M. 1994. Organosilicone surfactants: Tools for horticultural crop protection. BCPC - Pests and Diseases: 755-760.

Walker, J.T.S., Shaw, P.W. and Stevens, P.J.G., 1992. Evaluation of Silwet L-77 as an adjuvant for sprays to control apple pests and diseases. Proc. 45th N.Z. Plant Prot. Conf:: 274-278. 